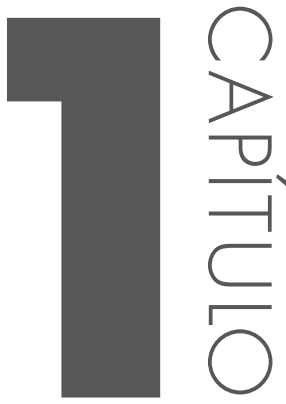

\title{
A ANTIGA CONCORRÊNCIA ENTRE AS FORMAS VERBAIS TER E HAVER: VARIAC̣ÃO E RETENC̣ÃO
}

\section{Sueli Maria Coelho (UFMG)*}

*Professora adjunta de Língua Portuguesa da Faculdade de Letras da Universidade Federal de Minas Gerais e pesquisadora filiada ao Núcleo de Pesquisa da Variação (NUPEVAR) da FALE/UFMG. 


\section{Considerações iniciais}

A despeito de o falante nem sempre ter consciência do caráter dinâmico da língua, ele é o agente implementador da variação e da mudança linguística, já que é aquele que, ao longo do processo, detém - poder de permitir que uma variante inovadora se mantenha como tal ou venha a configurar uma mudança. A generalização sociolinguística de que nem toda variação acarreta mudança aplica-se à vivaz concorrência entre as formas verbais ter e haver na Língua Portuguesa. Se, em alguns contextos, tais formas comportam-se como variantes linguísticas, por serem dotadas do mesmo valor de verdade, em outros, porém, especialmente naqueles 
em que a forma simples já se gramaticalizou em auxiliar de modalidade, parece haver restrições quanto à equivalência funcional, o que inviabiliza a afirmação de que, em tais contextos, as formas são concorrentes, conforme ilustram estes contextos ${ }^{1}$ :

(1) a. Há ainda muitos manifestantes na praça Tahrir, no centro do Cairo. b. Tem ainda muitos manifestantes na praça Tahrir, no centro do Cairo.

(2) a. A imprensa havia noticiado casos de violência contra os manifestantes. b. A imprensa tinha noticiado casos de violência contra os manifestantes.

(3) a. O Presidente Hosni Mubarak há de renunciar para evitar o caos.

b. O Presidente Hosni Mubarak tem de renunciar para evitar o caos.

Enquanto nos enunciados (1) e (2) haver e ter são variantes linguísticas, em (3) não se pode admitir tal fato, dado que a modalidade linguística impingida pelo falante em (3a) difere daquela presente em (3b), o que demonstra haver/existir contextos de distribuição complementar entre as formas. Frente a tal constatação, não se pode admitir que ter e haver são sempre formas concorrentes na língua e que apenas fatores diafásicos, ligados ao maior ou ao menor grau de formalidade, determinariam a seleção do falante. Como mostram os exemplos arrolados, fatores outros, especialmente de ordem sintático-pragmática, atuam no fenômeno de variação dessas formas, contribuindo para a retenção de haver, problema que este texto se propõe a abordar à luz do quadro teórico da sociolinguística variacionista.

Tal discussão reveste-se de significância, dado que, não raro, ouvemse declarações de que o verbo haver já é quase um arcaísmo linguístico e de que está fadado a desaparecer do idioma, sendo substituído pelo verbo ter. Essas previsões embasam-se apenas na observação de contextos em que a substituição já se deu de modo progressivo, como nas perífrases do pretérito perfeito composto do indicativo, por exemplo, ou naqueles em que o ter é a variante mais produtiva. Parece relevante, contudo, analisar tal fenômeno em tempo real, tentando interpretar os fatores que estão, ao longo dos séculos, atuando na substituição ou na retenção das formas, com vistas a traçar um panorama descritivo mais fiel desses fatos linguísticos, delineando, inclusive, contextos que configuram variação.

${ }^{1}$ Ao longo deste texto, os contextos nos quais não há indicação de autoria foram criados pela autora. 
Visando a cumprir tal proposta, este estudo extrai implicações de uma pesquisa que tomou como objeto de análise dados coletados em três períodos linguísticos classificados segundo cronologia proposta por Mattos e Silva (1989) e endossada por llari (1992) e por Maia (1995): período arcaico (intervalo de tempo que vai do séc. XIV ao XVI), período moderno (intervalo de tempo que compreende os séc. XVII e XVIII) e período contemporâneo (representado pelos séc. XX e XXI). Para a composição do corpus, selecionaram-se quatro textos representativos de cada um dos períodos ${ }^{2}$ ora delimitados, totalizando-se doze textos, nos quais se computaram todas as ocorrências das formas verbais em estudo, quer na sua ocorrência como forma simples (item lexical), quer como verbo auxiliar (item gramatical). A partir da análise da frequência, bem como de fatores semânticos e sintático-pragmáticos que envolvem o processo de variação e mudança das formas ter e haver, chegou-se às questões que passam a ser discutidas ao longo deste texto, que está assim organizado: na primeira seção, analisa-se, tomando como parâmetro a frequência total e as acepções semânticas, a concorrência entre as formas ter e haver cuja gênese remonta ao período arcaico da língua. Na seção seguinte, há uma tentativa de se relacionar as alterações de frequência e a deslexicalização da variante haver com o processo de variação e mudança linguística pelo qual ela passou quando da gramaticalização de auxiliar de diátese a auxiliar de temporalidade. Nas seções subsequentes, analisam-se os contextos em que as formas em estudo comportam-se como variantes linguísticas, cotejando-os com aqueles em que ter e haver aparecem em distribuição complementar, no intuito de se descrever possíveis contextos de substituição e de retenção, sintese apresentada nas considerações finais.

\footnotetext{
${ }^{2}$ Como representantes do período arcaico, analisaram-se trechos do Livro de Linhagens, cartas de D. Pedro e do Conde de Arraiolos, excertos da Crônica do Rei D. João e atas da Câmara de Vereadores da cidade de Funchal (Portugal). No período moderno, selecionaram-se textos de cunho moral e fábulas para serem lidas pelas religiosas nos mosteiros, um tratado sobre a forma de se conduzir um engenho de cana-de-açúcar, documentos cartoriais de Barra Longa (MG) e pronunciamentos proferidos na Arcádia Lusitânia. Por fim, o conto Sarampalha, de Guimarães Rosa, bulas de medicamentos, matérias e crônicas esportivas e políticas, além de três capítulos de uma dissertação compuseram o corpus representativo do período contemporâneo.
} 


\section{TER VERSUS HAVER: Uma concorrência de estirpe pré-carcaica}

Conforme se mencionou, a concorrência entre as formas ter e haver já se arrasta por séculos na língua, segundo comprovam os índices de frequência total dessas formas ao longo dos três períodos analisados e dispostos na tabela 1, a seguir.

TABELA 1: Análise comparativa da frequência das variantes por período.

\begin{tabular}{lcccccc}
\hline & \multicolumn{2}{c}{$\begin{array}{c}\text { Período arcaico } \\
\text { Total de palavras: } 33969\end{array}$} & \multicolumn{2}{c}{ Período moderno } & \multicolumn{2}{c}{ Periodo contemporâneo } \\
& Ocorrência & Porcentagem & Ocorrência & Porcentagem & Ocorrência & Porcentagem \\
\hline TER & 163 & 34,82 & 204 & 43,77 & 209 & 79,46 \\
HAVER & 268 & 62,18 & 262 & 56,23 & 54 & 20,54 \\
TOTAL & 431 & $100 \%$ & 466 & $100 \%$ & 263 & $100 \%$ \\
\hline
\end{tabular}

Fonte: COELHO (2006)

A análise estatística dos dados mostra que, no período arcaico, a concorrência já se encontrava bastante acirrada, o que induz ao raciocínio de que o processo de variação entre as duas formas iniciou-se num estágio anterior da língua. Além disso, a análise diacrônica da variação permite traçar uma curva ascendente nos usos de ter, o que se forma na contramão das ocorrências de haver. Enquanto, no período arcaico, a forma haver sobrepunha-se à forma inovadora ter, no período contemporâneo, tal sobreposição é da forma inovadora, que supera, em termos de frequência, a forma conservadora. Dado que processos de variação e mudança linguística se dão, geralmente, de forma encaixada, tais índices devem ser interpretados na imbricação com fatores semânticos, buscando-se identificar possíveis intersecções de sentidos entre as formas em análise, bem como os efeitos disso nos domínios do léxico. Há de se considerar ainda a possibilidade 
de processos ligados à gramaticalização das formas também interferirem no processo de variação e mudança, conforme se tentará demonstrar nos parágrafos que se seguem.

Uma consulta ao dicionário etimológico revela uma confluência de semas entre as duas formas analisadas: "haver: vb. 'ter', 'possuir', 'alcançar', 'considerar', 'existir'" (CUNHA, 1997, p. 404); "ter: vb. 'estar na posse de', 'possuir', 'haver'" (op. cit., p. 764). O fato de as formas verbais exibirem semas comuns já em sua origem faculta, sem dúvida, a variação e, conforme endossam as palavras de Mattos e Silva (2001 [1994]), coube ao sema responsável pela expressão da posse o desabrochar do processo de variação:

No período arcaico (h)aver e teer não estavam, no princípio, em variação livre nas estruturas de posse: (h)aver ocorria com complemento de qualquer valor semântico - bens materiais adquiríveis (a), qualidades imateriais adquiríveis (b), qualidades intrínsecas ao sujeito (c). Do século XIV para o XV $[\ldots]$, se pode observar que těĕr só ocorria comutando com (h) aver com atributos do tipo a e, menos freqüentemente, do tipo b; na primeira metade do século XV aparece těĕr/teer nos três "tipos de posse", sendo ainda (h)aver mais frequente; já na segunda metade do mesmo século se evidencia o recesso de (h)aver e o avanço de teer com os três tipos de atributo. (MATTOS E SILVA, 2001, p. 78)

O fato de ter passar a ser empregado com os três tipos de atributo, outrora restritos a haver, contribui certamente para o avanço da forma inovadora sobre a conservadora, mas pode não ser o único fator a exercer esse tipo de influência. Estudos já empreendidos (cf. COELHO, 2006) demonstraram que o processo de gramaticalização de haver em auxiliar dos tempos compostos é anterior ao de ter e que, no período arcaico da língua, o verbo haver já estava bastante gramaticalizado, enquanto o verbo ter encontrava-se num estágio inicial do processo. Estudiosos do tema são unânimes em afirmar que uma das consequências da gramaticalização é a expansão semântica por que passam os itens envolvidos, já que a tramitação dos domínios do léxico para os da gramática requer perda de conteúdo semântico e ganho de funções gramaticais. Assim, ao se gramaticalizar, o item caminha unidirecionalmente do [+concreto] para o [+abstrato]. Tal 
percurso afeta o léxico ${ }^{3}$, porque o processo de abstração, num estágio mais inicial, amplia os semas do item, contribuindo para a sua polissemia e, consequentemente, para o aumento de sua frequência. Nesse estágio, ocorre uma lexicalização da forma, ou seja, amplia-se a sua capacidade de referenciação, facultada pelo aumento de seus semas abstratos. Num estágio mais avançado do processo, quando há o esvaziamento semântico para a incorporação de funções gramaticais, ocorre, geralmente, o processo inverso, ou seja, a deslexicalização do item. A análise diacrônica dos valores semânticos das duas formas em estudo, dispostos nas tabelas 2 e 3, a seguir, endossam isso.

Tabela 2: Valores semânticos de HAVER

\begin{tabular}{|c|c|c|c|}
\hline Valores semånticos & $\begin{array}{l}\text { Periodo arcaico } \\
\text { Ocorrência (\%) }\end{array}$ & $\begin{array}{l}\text { Período moderno } \\
\text { Ocorrência (\$) }\end{array}$ & $\begin{array}{c}\text { Período } \\
\text { contemporáneo } \\
\text { Ocorrência (\%) }\end{array}$ \\
\hline estar na posse de, possuir & 32,74 & 11,80 & 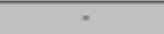 \\
\hline haver, existir & 25,60 & 65,60 & 70,30 \\
\hline considerar, julgar & 10,12 & 8,80 & $\cdot$ \\
\hline obter, conseguir & 19,00 & 2,00 & - \\
\hline fazer, realizar & 4,18 & $\cdot$ & \\
\hline ter transcorrido tempo & 2,98 & 4,90 & 29,70 \\
\hline dar, conceder & 1,79 & $\cdot$ & $\cdot$ \\
\hline travar, empreender & 1,19 & $\cdot$ & - \\
\hline permanecer, ficar & 0,60 & - & - \\
\hline vencer, alcançar êxito & 0,60 & * & * \\
\hline sentir, experimentar & 0,60 & $\cdot$ & $\cdot$ \\
\hline suceder, acontecer, ocorrer & 0,60 & $\cdot$ & - \\
\hline ter trato com, lidar & $\cdot$ & 4,90 & $\cdot$ \\
\hline proceder, portar-se, comportar-se & $\cdot$ & 1,00 & $\cdot$ \\
\hline levar, conduzir & * & 1,00 & - \\
\hline
\end{tabular}

Fonte: Coelho (2006)

\footnotetext{
${ }^{3}$ Para uma discussão mais aprofundada, consultar COELHO, S. M. Expansão gramatical e expansão lexical: dois processos linguísticos paralelos. In.: VITRAL, L. T; COELHO, S. M. Estudos de processos de gramaticalização em português: metodologias e aplicações. Campinas: Mercado de Letras, 2010.
} 
Tabela 3: Valores semânticos de TER

\begin{tabular}{|c|c|c|c|}
\hline Valores seminticos & $\begin{array}{l}\text { Periodo arcaico } \\
\text { Ocorrência (\%) }\end{array}$ & $\begin{array}{l}\text { Periodo moderno } \\
\text { Ocorrência (x) }\end{array}$ & $\begin{array}{c}\text { Periodo contemporâneo } \\
\text { Ocorréncia (\%) }\end{array}$ \\
\hline estar na posse de, possuir & 35,17 & 39,35 & 7,50 \\
\hline haver, existir & 17,24 & 9,03 & 10,83 \\
\hline apresentar, mostrar & 15,17 & 12,26 & 18,33 \\
\hline alcanқar, conseguir, obter & 11,03 & 3,23 & 11,67 \\
\hline dispor de & 8,97 & 12,90 & 21,67 \\
\hline acreditar & 4,14 & - & - \\
\hline manter & 2,07 & 12,90 & 5,83 \\
\hline gozar, desfrutar & 1,38 & 0,65 & 10,00 \\
\hline considerar, julgar & 1,38 & 0.65 & 0,83 \\
\hline adotar, proceder & 1,38 & - & $\cdot$ \\
\hline estar & 0,69 & $\cdot$ & $\cdot$ \\
\hline dispensar, despender & 0,69 & - & $\cdot$ \\
\hline encontrar-se com & 0,69 & 0,65 & . \\
\hline sentir, experimentar & $=$ & 6,45 & 5,00 \\
\hline produzir, efetuar & * & 1,28 & - \\
\hline acolher, abrigar, hospedar & $\cdot$ & 0,65 & $\cdot$ \\
\hline tomar por parâmetro & $\cdot$ & - & 3,34 \\
\hline sofrer ou padecer de & * & $\cdot$ & 2,50 \\
\hline acontecer, suceder & $\cdot$ & $\cdot$ & 1,67 \\
\hline receber, ser punido com & * & $=$ & 0,83 \\
\hline
\end{tabular}

Fonte: Coelho (2006)

É possível estabelecer uma correlação proporcional lógica entre o aumento diacrônico da frequência de ter e sua expansão semântica. Tal expansão é decorrente de seu estágio inicial de gramaticalização, que o torna mais polissêmico, em virtude da abstração que o processo envolve. Os dados referentes à lexicalização de ter (cf. tabela 3) mostram não apenas a especialização de alguns sentidos, que aumentam seus índices percentuais ao longo dos três períodos, como também o surgimento de novas acepções, tanto no período moderno, quanto no contemporâneo. Por outro lado, o verbo haver, cujo processo de gramaticalização já estava mais consolidado, experimenta não a polissemia, mas a restrição de seus 
semas em virtude do esvaziamento semântico que a incorporação de traços gramaticais de tempo, modo, pessoa e aspecto exigem. Identificaram-se, no período moderno, ainda que com baixas ocorrências, valores semânticos não identificados no período arcaico, mas que desapareceram no período contemporâneo. Neste se mantiveram apenas os dois sentidos que foram se firmando ao longo dos três períodos. Vê-se, pois, que os estágios distintos de gramaticalização dos verbos ter e haver em auxiliares também afetaram semanticamente as duas formas concorrentes, atuando como outro fator interveniente no processo de mudança.

\section{Uma concorrência desconhecida \\ sincronicamente}

Ao longo da história da língua, o verbo haver não enfrentou apenas a concorrência com o verbo ter, que perdura até a contemporaneidade. $\mathrm{Na}$ fase do Romance, em que se verificou a dialetação do latim e o surgimento de certas fronteiras linguísticas, o verbo haver integrou outro processo de variação no qual concorria com o verbo ser como uma variante na auxiliaridade de passiva. Vincent (1982), ao discorrer sobre a gramaticalização dos verbos haver e ser no Romance, afirma que ambas as formas eram empregadas, nesse período linguístico, como auxiliares de passiva. Acrescenta, ainda, que, naquela época, o verbo haver passou a incorporar a função de auxiliar de diátese, enquanto o verbo ser apenas a expandiu, uma vez que já era assim empregado nas línguas clássicas. Segundo o autor referenciado, o verbo haver lexical requer dois argumentos: um locativo (sintagma preposicional) e um neutro (objeto). O neutro constitui o "gatilho" entre haver e o seu verbo acompanhante na forma de particípio. Na maioria dos casos, as circunstâncias é que determinam a identificação do locativo de haver com o neutro do verbo particípio e é essa identificação a responsável por promover a gramaticalização da forma. Nas palavras do autor, "haver não mais seleciona seu próprio locativo, mas preenche aquela posição em sua estrutura pela promoção de um agente não expresso do verbo ao qual ele se liga pelo 'gatilho' neutro 4. ." (p. 84, tradução minha) Assim, pode-se afirmar que "a gramaticalização de haver envolve ${ }^{4}$ Do original: "[...] habere no longer selects its own LOC but fills that position in its structure by promotion of the unexpressed AG of the verb to which it is attached by the NEUT 'hinge'." (VINCENT, 1982, p. 84) 
a retenção de seus papéis gramaticais - sujeito e objeto - mas a perda de seu independente papel semântico de locativo ${ }^{5}$." (op. cit., p. 85, tradução minha)

A auxiliarização de temporalidade, um dos contextos em que contemporaneamente se manifesta a concorrência entre ter e haver, é, como demonstrado, diacronicamente posterior à auxiliarização de diátese, quando o verbo haver concorreu com o ser. Segundo Green (1982), o uso de haver como um auxiliar de temporalidade é o resultado de uma reanálise de seu emprego originalmente passivo. Assim, as perífrases de haver + particípio são estágios mais gramaticalizados dessas perífrases empregadas para marcar a auxiliarização. Nas palavras de Green (1982),

essencialmente, e com muito poucas exceções, a concordância mostra que o particípio passado é passivo. Dessa forma, a presença da concordância sistematicamente marca o particípio de passividade enquanto sua ausência marca a completa gramaticalização de haver + particípio, em que o particípio é interpretado como [+ perfectivo, - passivo]; ao mesmo tempo, a concordância obrigatória do objeto de alguns verbos [...] serve como um lembrete patente de que nessas construções os verbos não estão plenamente gramaticalizados e retêm uma parte dos seus sentidos lexicais normais ${ }^{6}$ (p. 110 , tradução minha)

O fato de o verbo haver já ter enfrentado a concorrência com o ser deve ser considerado na análise de seu processo de variação com ter por, basicamente, dois motivos: (i) a concorrência com outra forma verbal, em decorrência de fatores distintos e com funções distintas, atesta a multifuncionalidade de haver no idioma, característica que pode favorecer sua retenção em determinado(s) contexto(s); (ii) a concorrência com outra forma certamente também interferiu

5 Do original: "[...] the grammaticalisation of habere involves the retention of its grammatical roles subject and object - but the loss of its independent semantic role of LOC." (VINCENT, 1982, p. 85)

${ }^{6}$ Do original:"Essentially, and with very few exceptions, concord shows that the past participle is passive. Thus, presence of concord systematically marks the participle for passivity while its absence marks the complete grammaticalization of haber + participle, in which the participle is interpreted as [+ perfective, - passive]; at the same time, obligatory concord on the objects of some transitive verbs (...) serves as an overt reminder that in these constructions the verbs are not fully grammaticalised and retain a part of their normal lexical meaning." (GREEN, 1982, p. 110) 
em seu semema e na restrição/ampliação de seus contextos, o que refletirá no processo de variação atual.

\section{Contextos em que TER E HAVER são formas variantes}

Como ilustrado pelos enunciados do grupo (1) apresentados nas considerações iniciais e aqui repetidos apenas por comodidade para o leitor, a forma simples do verbo é um dos contextos que favorecem a concorrência entre ter e haver, especialmente na acepção de "existir":

(1) a. Há ainda muitos manifestantes na praça Tahrir, no centro do Cairo.

b. Tem ainda muitos manifestantes na praça Tahrir, no centro do Cairo.

Outro contexto em que ter e haver são variantes linguísticas é aquele em que essas formas verbais indicam tempo transcorrido, conforme ilustrado em (4):

(4) a. Há um mês que Pedro não aparece por aqui.

b. Tem um mês que Pedro não aparece por aqui.

Cumpre assinalar que, nessa acepção semântica, o conjunto das variantes não se restringe às duas formas em estudo, já que o verbo fazer (cf. 4c) também é bastante produtivo no contexto, o que, possivelmente, interferirá na vitória de uma das variantes.

(4) c. Faz um mês que Pedro não aparece por aqui.

No tocante aos contextos de tempos compostos, quando ter e haver são formas auxiliares e, como tais, elementos gramaticais, as construções exibem certas restrições sintáticas próprias do processo de gramaticalização, - que também pode interferir no processo de mudança das variantes. Tanto ter quanto haver selecionam as formas nominais de particípio e de infinitivo para co-ocorrerem com eles nas perífrases verbais, não admitindo, portanto, a co-ocorrência com o gerúndio. A despeito de selecionarem as mesmas formas nominais para integrarem as perífrases, a produtividade dos auxiliares se diferencia em relação à forma nominal selecionada: enquanto 
as perífrases de ter, em todos os três períodos analisados, ocorreram prioritariamente com o particípio, as perífrases de haver, nos períodos arcaico e moderno, eram majoritariamente compostas pelo infinitivo. Apenas no período contemporâneo as perífrases com o particípio tornaram-se mais frequentes na língua, embora ainda sejam muito recorrentes as perífrases com o infinitivo, o que já sinaliza uma possível especialização de contextos.

Em se tratando de tempos compostos, o pretérito mais-que-perfeito, conforme ilustrado nas considerações iniciais, é também um contexto em que a concorrência se manifesta:

(2) a. A imprensa havia noticiado casos de violência contra os manifestantes. b. A imprensa tinha noticiado casos de violência contra os manifestantes.

Ainda que se identifique no enunciado (2a) um estilo mais formal que no enunciado (2b), em ambas as perífrases nota-se a expressão de uma ação passada anterior ao ato enunciativo. No tocante às funções dos elementos constituintes dessas perífrases, compete à forma nominal de particípio a expressão da perfectividade e, ao auxiliar haver/ter, a expressão da anterioridade. No estágio atual da língua, entretanto, conforme pontua Câmara Júnior (1998 [1969]),

o pretérito mais-que-perfeito é de rendimento mínimo na língua oral, mesmo de registro formalizado de dialeto social culto; ou se emprega, em seu lugar, o pretérito perfeito, que não está formalmente marcado, como sucede com ele; ou se substitui por uma locução de particípio com o verbo auxiliar ter no pretérito imperfeito (tinha cantado em vez de cantara). (p. 100)

As perífrases de pretérito mais-que-perfeito constituem, talvez, um dos contextos de maior concorrência entre ter e haver na contemporaneidade e, a julgar pela produtividade das duas construções, a forma inovadora provavelmente sairá vitoriosa. Como relatam as palavras de Câmara Júnior (1998 [1969]), existe um encaixamento de mudança a atuar neste contexto, porque, ainda que na expressão do pretérito mais-que-perfeito a preferência do falante seja pela forma composta, a produtividade do auxiliar haver é bastante limitada; prioriza-se o auxiliar ter, provavelmente em virtude de seu teor mais coloquial, apesar de o emprego de haver traduzir aproximadamente a mesma carga semântica.

Em se tratando dos compostos do modo subjuntivo, os auxiliares 
haver e ter parecem se equivaler funcionalmente em todos os tempos, como demonstram os enunciados de (5) a (7), apresentados a seguir:

(5) a. Espero que Maria haja frequentado os melhores colégios.

b. Espero que Maria tenha frequentado os melhores colégios.

(6) a. Se Maria houvesse frequentado os melhores colégios, certamente teria sido aprovada no processo seletivo.

b. Se Maria tivesse frequentado os melhores colégios, certamente teria sido aprovada no processo seletivo.

(7) a. Quando Maria houver concluído o curso superior, conseguirá um ótimo emprego.

b. Quando Maria tiver concluído o curso superior, conseguirá um ótimo emprego.

A equivalência ora ilustrada diz respeito ao valor de verdade das duas variantes, resguardando-se a variação estilística entre elas. $\bigcirc$ fato de os enunciados $b$ serem mais coloquiais que aqueles apresentados em $a$ certamente contribui para a sua maior produtividade, o que poderá, com o avançar do processo de mudança, culminar com a vitória da variante ter. Considerando-se que o modo subjuntivo é menos produtivo na língua que o indicativo, já que seu uso é preterido, principalmente por falantes de menor escolaridade, espera-se que o desaparecimento de haver, caso venha a ocorrer, se dê primeiramente no pretérito mais-que-perfeito composto do modo indicativo.

\section{Contextos em que TER e HAVER estão em distribuic̣ão complementar}

Contextos há, contudo, em que não se pode falar em variação, uma vez que as formas ter e haver não podem ser permutadas, sob pena de se produzirem sentenças agramaticais ou de se alterar significativamente 0 sentido/intenção dos enunciados. Um desses contextos é o pretérito perfeito composto do modo indicativo. Nessa flexão, apenas a forma ter produz enunciados gramaticais, conforme ilustram estes exemplos: 
(8) a. * Maria há feito exercícios físicos regularmente.

b. Maria tem feito exercícios físicos regularmente.

Nenhum falante do português contemporâneo hesitaria em classificar o enunciado (8a) como agramatical. A ideia de repetição ou de prolongamento de um fato até o momento de sua enunciação é traduzida pela perífrase destacada em (8b), mas não por aquela empregada em (8a). Apenas nos períodos arcaico e moderno registraram-se ocorrências de perífrases constituídas de verbo haver flexionado no presente do indicativo mais particípio. Ainda assim, as ocorrências foram todas com a primeira pessoa; jamais com a segunda ou com a terceira. $O$ desaparecimento dessas perífrases na contemporaneidade demonstra que, neste contexto, a mudança já se sagrou, com a vitória da variante inovadora. Em outras palavras, os enunciados do tipo (8b) não devem fazer parte do rol dos dados a serem submetidos à quantificação.

Nas perífrases formadas de auxiliar + infinitivo, as restrições gramaticais quanto à seleção das variantes são ainda maiores que naquelas constituídas de auxiliar + particípio, pois parece não haver equivalência de sentido em nenhum dos tempos, segundo ilustram os exemplos (9) e (10):

(9) a. Maria há de estudar nos melhores colégios.

b. Maria tem de estudar nos melhores colégios.

(10) a. Maria tinha de estudar nos melhores colégios.

b. Maria havia de estudar nos melhores colégios

Quando os auxiliares haver e ter agregam-se às formas nominais de infinitivo, a permuta do presente pelo pretérito imperfeito não produz enunciados agramaticais, como ocorre quando a perífrase é constituída com - particípio. Isso ocorre porque a combinação do auxiliar com o particípio não altera a transitividade da primeira forma verbal integrante da perífrase. Por outro lado, nas combinações com o infinitivo, o auxiliar, "de nocional, passa a funcionar como relacional" (SAID ALl, 2001 [1921], p. 124). É em virtude dessa modificação que o processo opera na transitividade do auxiliar que, ao contrário do que se verifica com as perífrases de particípio, o valor semântico das formas verbais não se aproxima. Em (9a), identificase o desejo do enunciador de que a ação verbal se efetive; em (9b), a modalidade não é optativa, mas deôntica, ou seja, a forma perifrástica 
traduz uma necessidade da qual não se abdica, chegando a se impor como uma obrigatoriedade. Em (10a), a modalização do enunciador soa mais como um lamento por algo que não se efetivou, enquanto em (10b) percebese um tom de predestinação, indicando que a ação expressa pela perífrase verbal independe da vontade do sujeito do enunciado.

Os dados coletados demonstram que, em se tratando da auxiliarização de modalidade, ter e haver não são formas variantes, já que não são intercambiáveis em todos os contextos, mas estão em distribuição complementar. A análise empreendida acena ainda na direção de que são justamente as perífrases de infinitivo, preferidas nos períodos arcaico e moderno, que mantêm o auxiliar haver no sistema linguístico do português contemporâneo, dado ser esse, no estágio atual da língua, o contexto em que a substituição entre as formas não altera apenas o teor de formalidade do discurso.

Consideremos, a seguir, os contextos em que a modalidade expressa pelos auxiliares ter e haver parece não ser mais tão dicotômica como se verifica nos contextos descritos em (9) e em (10).

(11) a. Há de se considerar a possibilidade de uma reanálise semântica. b. Tem de se considerar a possibilidade de uma reanálise semântica.

(12) a. Ele há de conseguir aquele emprego; afinal se esforçou tanto! b. Ele tem de conseguir aquele emprego; afinal se esforçou tanto!

No enunciado (1 1), a sequência [auxiliar+infinitivo] tem como sujeito um NP impessoal. No enunciado (12), essa sequência participa de uma oração exclamativa. Tanto em (1 la) como em (1 l b), não se nota um desejo de que a ação expressa pelo infinitivo venha a se efetivar, mas existe um alerta para o caráter imperativo de se considerar a possibilidade de uma reanálise semântica. Tanto o enunciado (12a) quanto o (12b) constituem contextos pragmaticamente optativos. Esses enunciados constituem evidências em favor da tese de que o falante está reanalisando semanticamente as perífrases constituídas de ter/haver + infinitivo. Assim, em contextos nos quais o verbo haver deveria ser interpretado como um instaurador de desejo em relação à ação expressa pela forma infinitiva, ele passa a ser interpretado como uma marca de forte necessidade, como a expressão de uma ação da qual não se pode abdicar. Em contrapartida, o verbo ter, que usualmente se presta à função de instaurar a obrigatoriedade de que a ação verbal venha a se efetivar, em alguns contextos, está sendo interpretado como um marcador de 
volição.

Identificados os diferentes condicionamentos que atuam sobre a alternância haver/ter, resta tentar descrever como essa reanálise semântica está se processando. Os exemplos arrolados também se mostram úteis nessa tarefa: a reanálise de haver como um marcador de obrigatoriedade, de forte necessidade, acontece em contextos argumentativos, geralmente com o sujeito apassivado; a reanálise de ter como um marcador de desejo ou de volição acontece quando a ação expressa pelo verbo independe da vontade ou mesmo da iniciativa do sujeito do enunciado. Além dessa distinção de ordem sintático-pragmática, os traços suprassegmentais também exercem importante papel no processo de reanálise semântica. A forma como o enunciador profere o enunciado auxilia na identificação da forma como ele deve ser interpretado. Desvinculado de seu contexto de produção, o enunciado (13) pode soar ambíguo:

(13) Maria tem de conseguir este prêmio.

Se o enunciador profere esse enunciado com um tom de voz mais áspero, mais impositivo, o enunciatário pode interpretá-lo como a expressão de uma obrigatoriedade, mas se, contrariamente, o tom de voz empregado pelo enunciador for mais meigo, próprio de contextos optativos, o enunciatário irá processá-lo como sendo a manifestação do desejo de que Maria consiga o prêmio. A ambiguidade de interpretação desse enunciado é um apelo à necessidade de se levar em conta contextos mais amplos e também elementos prosódicos, quando possível, na seleção dos dados que vão compor um corpus a ser submetido à análise quantitativa. Feito o recorte adequado, as formas não variantes serão excluídas. Estas constituem formas que assumem valores funcionais distintos e não devem, pois, compor o conjunto de variantes a serem analisadas. A despeito da existência de uma reanálise semântica em curso, esses fatos comprovam que, mesmo tendo enfrentado a concorrência com o auxiliar ter em alguns contextos, o auxiliar haver apresenta ainda contextos de exclusividade e, portanto, não está condenado a desaparecer do idioma tão rapidamente, como professa a voz do senso comum. 


\section{Considerações finais}

Este estudo foi motivado pela pretensão de se verificar cientificamente a autenticidade da recorrente afirmação de que o verbo haver está desaparecendo da língua, sendo substituído por seu concorrente ter, variação desencadeada há vários séculos em decorrência de as duas formas exibirem em comum o sema destinado à expressão da posse. Alguns entusiastas mais precipitados chegam mesmo a afirmar que o referido verbo já é um arcaísmo linguístico, especialmente nos tempos compostos. Ribeiro (1993), citando Said Ali (1967), endossa a tese defendida por esse linguista de que "são as formas compostas com o verbo ter as mais usadas; a combinação do auxiliar haver com o PtP [particípio passado], empregada com moderação, dá à linguagem feição mais solene; empregada sistematicamente, torna-a rebuscada e pedante." (RIBEIRO, 1993, p. 344-345, grifos do autor). Os dados cotejados e as discussões aqui levantadas demonstram, porém, que a seleção dos auxiliares ter e haver não é determinada meramente por fatores de natureza situacional. Não se está aqui contestando que o haver impinge um tom mais formal ao enunciado que o auxiliar ter. Entretanto, há de se considerar que a substituição de uma forma pela outra não é lícita em todos os tempos e modos, tampouco obedece ao mesmo critério, caso a perífrase seja constituída pela forma nominal de particípio ou de infinitivo, donde se pode concluir que, em se tratando da auxiliarização de temporalidade, existe a restrição estilística, mas esta não se estende analogicamente à auxiliarização de modalidade.

Frente à análise empreendida, é possível descrever os contextos de uso dos verbos ter e haver, no estágio atual da língua:

(a) Quando empregadas como formas simples, nas acepções de "existir" e de "indicar tempo decorrido", as duas formas são variantes e, em virtude do teor menos formal de ter, esta é a forma mais produtiva.

(b) Quando se trata do pretérito mais-que-perfeito composto do indicativo, a probabilidade de esse auxiliar ser o verbo haver é bastante reduzida, pois, embora as duas formas sejam variantes, também nesse contexto, a preferência é pelo auxiliar ter. Não se descarta, portanto, a possibilidade de que, nesse contexto distribucional, o auxiliar haver venha a desaparecer da língua, mesmo nos contextos de maior formalidade. 
(c) Quando se tratar de perífrases do pretérito imperfeito do indicativo, esse auxiliar jamais será o haver, pois, nesse contexto, o auxiliar ter já o substituiu, desde o período moderno da língua.

(d) Quando o auxiliar estiver flexionado em um dos tempos do modo subjuntivo + particípio, existe a possibilidade de tal auxiliar ser tanto o haver quanto o ter, pois, nesse contexto, as duas formas parecem se equivaler funcionalmente, embora se mantenha a restrição estilística e a consequente predileção pela variante ter.

(e) Em se tratando de perífrases com o infinitivo, em qualquer tempo e modo, a probabilidade de se encontrar ora o auxiliar ter ora o haver subordina-se a fatores pragmáticos, tendo em vista que ambos ainda traduzem expressões diferenciadas de modalidade optativa (variante haver) e deôntica (variante ter), apesar da possibilidade que se vislumbra de uma reanálise semântica.

Não se pode, pois, endossar a afirmação de que a mudança linguística já se sagrou com a vitória de ter sobre haver. Embora, na maioria dos contextos, a produtividade de ter seja estatisticamente superior, existem contextos, especialmente de modalidade optativa, em que a preferência é pela variante haver, o que the assegura a retenção na língua, pelo menos por mais algum tempo. 


\section{Referências bibliográficas}

CÂMARA JÚNIOR, Joaquim Mattoso. Estrutura da língua portuguesa. 28. Ed. Petrópolis: Vozes, 1998.

COELHO, Sueli Maria Coelho (2006). Estudo diacrônico do processo de expansão gramatical e lexical dos itens TER, HAVER, SER, ESTAR e IR na Língua Portuguesa. 2006. (Tese de Doutorado em Estudos Linguísticos) Belo Horizonte: Faculdade de Letras da Universidade Federal de Minas Gerais.

CUNHA, Antônio Geraldo da. Dicionário etimológico Nova Fronteira da língua portuguesa. 2. ed. rev. e acrescida de um suplemento. 8. Impressão. Rio de Janeiro: Nova Fronteira. 1997.

GREEN, John N. The status of the romance auxiliaries of voice. In.: VINCENT, Nigel; HARRIS, Martin (orgs.) Studies in the Romance Verb. London: Croom Helm Ltd, 1982, p. 97-138.

ILARI, Rodolfo. Lingüistica românica. São Paulo: Ática, 1992.

MAIA, Clarinda de A. História da língua portuguesa: guia de estudo. Coimbra: Faculdade de Letras, 1995.

MATTOS E SILVA, Rosa Virgínia. Estruturas trecentistas: elementos para uma gramática do português arcaico. Imprensa Nacional - Casa da Moeda, 1989. (Estudos Gerais Série Universitária).

MATTOS E SILVA, Rosa Virgínia. O português arcaico: morfologia e sintaxe. 2. ed. São Paulo: Contexto, 2001. (Repensando a Língua Portuguesa). 
RIBEIRO, Ilza. A formação dos tempos compostos: a evolução histórica das formas ter, haver e ser. In.: ROBERTS, lan; KATO, Mary A. (orgs.). Português brasileiro: uma viagem diacrônica: homenagem a Fernando Tarallo. Campinas: Editora da Unicamp, 1993. cap. XI, p. 343-386.

SAID ALI, M. Gramática histórica da língua portuguesa. 8. ed. rev. e atual. por Mário Eduardo Viaro. Companhia Melhoramentos: Brasília: Editora Universidade de Brasília, 2001.

VICENT, Nigel. The development of the auxiliaries habere and esse in Romance. In.: VINCENT, Nigel; HARRIS, Martin (orgs.) Studies in the Romance Verb. London: Croom Helm Ltd, 1982, p. 71-96. 